\title{
Multidisciplinary Management of Hepatocellular Carcinoma: Where Are We Today?
}

\author{
Jorge A. Marrero, MD, MS ${ }^{1}$ \\ ${ }^{1}$ Medical Director of Liver Transplantation, UT Southwestern Medical \\ Center, Dallas, Texas \\ Semin Liver Dis 2013;33(S1):S3-S10.
}

\begin{abstract}
Address for correspondence and reprint requests Jorge A. Marrero, MD, MS, Medical Director of Liver Transplantation, UT Southwestern Medical Center, Professional Office Building 1, Suite 520L, 5959 Harry Hine Blvd., Dallas, Texas 75390-8887

(e-mail: Jorge.marrero@utsouthwestern.edu).
\end{abstract}

\begin{abstract}
Keywords

- hepatocellular carcinoma

- liver cancer

- BCLC staging

- sorafenib

Hepatocellular carcinoma (HCC) is the third most common cause of cancer-related death worldwide, and the incidence of HCC continues to rise. Improved understanding of risk factors for HCC has allowed the development of more effective prevention and surveillance strategies to reduce the global burden of this malignancy. Because of the complex nature of HCC, arising in a background of chronic liver dysfunction and often associated with viral infection, appropriate treatment requires a multidisciplinary approach designed to control the cancer and treat the underlying liver disease. Treatment approaches vary based on disease stage and severity, making accurate diagnosis and staging of disease critical. This has been aided by the development of new staging criteria, such as the Barcelona Clinic Liver Cancer Staging System. For earlierstage disease, resection, radiofrequency ablation, transplantation, and transarterial chemoembolization (TACE) are preferred treatment modalities that provide optimal outcome. Until recently, few treatment options existed for patients with more advanced disease. Improved understanding of the underlying biology of the disease and the development of molecularly targeted therapies, including the multitargeted angiokinase inhibitor sorafenib, has improved outcomes in this patient population. Research into therapeutic targets and novel agents continues for more advanced disease.
\end{abstract}

Hepatocellular carcinoma (HCC) is a complex and heterogeneous disease that occurs in the background of chronic liver dysfunction. It is a unique and particularly challenging cancer to treat because the dual forces of malignancy and underlying liver disease must be simultaneously managed. This review will outline current perspectives on epidemiological trends and risk factors for HCC; the roles of screening/surveillance, diagnostic, and treatment strategies; and the importance of adopting a multidisciplinary approach to HCC management.

\section{Epidemiology and Risk Factors of HCC}

Hepatocellular carcinoma is the third most common cause of cancer death worldwide, ${ }^{1}$ accounting for $\sim 695,900$ deaths yearly. ${ }^{2}$ Although the highest incidence of HCC is in Southeast and East Asia and sub-Saharan Africa, current epidemiologic trends show that the incidence of HCC in the United States is rising. ${ }^{3}$ Age-adjusted incidence rates from the Surveillance, Epidemiology, and End Results (SEER) registry show that the incidence of HCC has tripled between 1975 and 2005³ the American Cancer Society estimated 28,720 new cases of HCC and 20,550 HCC-related deaths in the United States in $2012 .{ }^{4}$ The incidence and associated mortality of HCC varies based on ethnicity and age. Asians/Pacific Islanders show the highest incidence followed by Hispanics, Blacks, American Indians/ Alaskan natives, and Whites. Among age groups, the highest increase in rates of HCC are found in men aged 50 to 59 years and 70 to 84 years. $^{3}$

Understanding the etiology and risk factors for HCC is important in appreciating global HCC trends and instituting appropriate prevention or screening approaches. Hepatitis B virus (HBV) is a well-known etiologic risk factor, and the high
Issue Theme Enhancing Clinical Outcomes in Hepatocellular Carcinoma; Guest Editor, Ghassan Abou-Alfa, MD
Copyright (c) 2013 by Thieme Medical Publishers, Inc., 333 Seventh Avenue, New York, NY 10001, USA. Tel: +1(212) 584-4662.
DOI http://dx.doi.org/ 10.1055/s-0033-1333631. ISSN $0272-8087$. 
incidence of HCC in China and Africa reflects the elevated prevalence of chronic HBV infection. ${ }^{2,5}$ However, HCC in the United States, Western Europe, and Japan more commonly arises in the context of liver injury due to chronic hepatitis $C$ virus $(\mathrm{HCV}){ }^{3,6}$ Other important risk factors implicated in the etiology of HCC include aflatoxin B1 exposure, alcoholic cirrhosis, diabetes, obesity, and nonalcoholic steatohepatitis (NASH). The risk of HCC was found to significantly increase with an alcohol exposure of $>80$ g ethanol per day compared with no exposure, and was elevated 54-fold in the presence of both viral infection and alcohol exposure. ${ }^{7,8}$ Patients with diabetes had a significantly higher incidence rate (2.39 vs 0.87 per 10,000 person-years, respectively, $p<0.0001$ ) compared with patients without diabetes in a study of 824,263 patients. ${ }^{9}$ In a large prospective study, a high body mass index (BMI) of 35.0-39.9 was associated with a 4.5-fold increased risk of HCC. ${ }^{10}$ Moreover, synergistic interaction among alcohol exposure, diabetes, and obesity might further increase the risk of $\mathrm{HCC}^{8}$ The relationship between tobacco use and risk of HCC is presently unclear; however, a casecontrolled study demonstrated a fivefold increase in the risk of HCC after an exposure of 20 pack-years. ${ }^{11}$

Given that chronic HBV and HCV infections are the major risk factors for HCC, prevention of these infections would have a huge impact on the worldwide incidence of HCC. Rigorous HBV vaccination measures have been highly successful in preventing both neonatally acquired HBV and adult HBV infections and consequently, in reducing the risk of HCC. ${ }^{12}$ In addition to vaccinations, some evidence indicates that antiviral therapies may play an important role in preventing complications from chronic HBV infection and progression to HCC. In a placebo-controlled study of 651 patients with chronic HBV infection, antiviral therapy with lamivudine reduced the incidence of HCC by $51 \%$ compared with placebo (3.9\% vs 7.4\%; hazard ratio $[\mathrm{HR}]=0.49 ; p=0.047) .{ }^{13}$ In the case of $\mathrm{HCV}$, where no vaccine is available, preventative strategies include disrupting transmission through good clinical practices, reducing high-risk behaviors through public education, and managing chronic infections with combined antiviral therapy including novel agents such as boceprevir or telapravir. ${ }^{14}$ Other, modifiable risk factors, such as alcohol use, diabetes, obesity, and smoking, will likely get more attention once preventative strategies against viral hepatitis are well implemented.

Prior to discussing diagnostic and treatment approaches for HCC, the implications of the heterogeneity of HCC and underlying liver disease must be underscored. Although it is known that up to $70 \%$ of HCC develops in the setting of chronic liver disease, ${ }^{15,16}$ the molecular evolution of HCC is a complex, multistep process that is still not completely understood. However, two major mechanisms seem to be the most important: the development of liver cirrhosis and the alteration of oncogenes and tumor suppressor genes leading to aberrant cell signaling pathways. Targeting these signaling pathways represents a rationale for modern systemic therapy of HCC and is discussed later in this supplement.

Due to the complex nature of HCC and its association with liver dysfunction, the management of this malignancy re- quires close collaboration among a multidisciplinary team of hepatologists/gastroenterologists, pathologists, radiologists, surgeons, and oncologists. Timely selection of a therapeutic intervention and referral to the appropriate specialist within the multidisciplinary team is critical to deliver optimal patient care in this disease.

\section{Surveillance and Diagnosis}

Screening and surveillance are highly important for early detection of HCC in patients considered to be at risk, such as Asian HBV carriers, Blacks with hepatitis B, HBV carriers with family history of HCC, patients with cirrhosis and chronic HBV or HCV, genetic susceptibility (hemochromatosis, $\alpha 1$-antitrypsin deficiency), or cirrhosis of other etiology. ${ }^{17}$

Hepatologists/gastroenterologists at the forefront of managing patients with chronic liver diseases play a critical role in the implementation of surveillance programs. The combination of ultrasound and $\alpha$-fetoprotein (AFP) evaluation has been shown to reduce mortality by $37 \%$ in patients with $\mathrm{HBV},{ }^{18}$ supporting the need for HCC surveillance. However, in a pooled analysis in patients with early HCC, ultrasound was shown to have only $63 \%$ sensitivity. ${ }^{19}$ Cost-effectiveness and cost-benefit analyses have indicated that the surveillance strategy of ultrasound and AFP appears to be the best, ${ }^{20,21}$ and a recent prospective study showed that ultrasound and AFP are complementary, with a sensitivity of $90 \%$ and specificity of $83 \%{ }^{22}$ The practice guidelines of the American Association for Liver Diseases (AASLD) recommend ultrasound alone at 6-month intervals for HCC surveillance, ${ }^{17}$ but the National Comprehensive Cancer Network (NCCN) and other societies recommend the combination of ultrasound and AFP. ${ }^{23}$ There is a need to identify novel biomarkers, either alone or to complement ultrasonography, to improve the performance characteristics for the detection of early HCC.

When suspicious nodules are identified, the current diagnostic algorithm (- Fig. 1) proposed by the AASLD recommends that liver nodules $<1 \mathrm{~cm}$ be observed with ultrasound every 3 months until stability or growth of the lesion is established. ${ }^{17}$ For lesions $>1 \mathrm{~cm}$, characteristic intense arterial uptake followed by contrast washout in the venous-delayed phases should be detected with 4-phase multidetector computer tomography (MDCT) or dynamic contrast-enhanced magnetic resonance imaging (MRI). With the improved accuracy and sensitivity of imaging modalities, liver biopsy is currently not indicated for the diagnosis of HCC in a cirrhotic liver, and is even considered controversial. Although specificity of liver biopsy is almost $100 \%$, sensitivity varies and depends on the tumor size and location and the size of the needle used for biopsy. Additionally, there is a small risk (2.7\%) of tumor seeding after liver biopsy. ${ }^{24}$ According to the AASLD guidelines, biopsy is warranted only in instances where neither MDCT nor MRI shows characteristics of HCC, and is most useful in hypovascular tumors and in small nodules $<1 \mathrm{~cm}$. ${ }^{17}$ Histologic confirmation of HCC requires positive results for at least two of the following three immunostains: glypican 3 , heat shock protein 70 , and glutamine synthetase. ${ }^{25}$ 


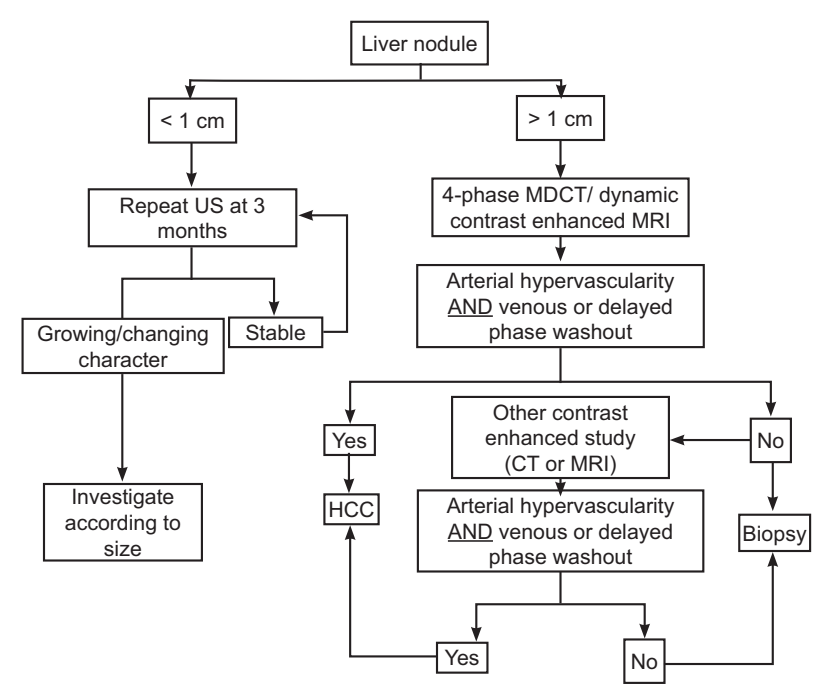

Fig. 1 Algorithm for diagnosis of hepatocellular carcinoma (HCC): American Association for Liver Diseases guidelines. ${ }^{17}$ US, Ultrasound; $\mathrm{MRI}$, magnetic resonance imaging; $\mathrm{CT}$, computed tomography; $\mathrm{MDCT}$, 4-phase multidetector computer tomography. (Reprinted with permission from Bruix J, et al. Hepatology 2011; 53(3):1020-1022. Copyright John Wiley and Sons.)

\section{Staging and Outcome of HCC}

Prognosis and treatment options for HCC are dependent not only on the tumor stage, but also on the magnitude of liver impairment; therefore, conventional staging systems used in the majority of other cancers, such as the tumor-nodemetastasis (TNM) staging system, are insufficient. Several HCC staging systems incorporating liver function, such as the Okuda classification, ${ }^{26}$ Cancer of the Liver Italian Program (CLIP), ${ }^{27,28}$ Chinese University Prognostic Index (CUPI), ${ }^{29}$ and Japanese Integrated System (JIS), ${ }^{30}$ have been developed; however, they do not adequately stratify patients across the continuum of HCC and fail to provide treatment guidance or prognostic accuracy. ${ }^{31,32}$ In contrast, the Barcelona Clinic Liver Cancer (BCLC) Staging System (-Fig. 2) stratifies patients based on tumor stage, performance status, cancerrelated symptoms, and liver function status as assessed by the Child-Pugh score to provide specific treatment recommendations that can be correlated with life expectancy. ${ }^{33-36}$ The Child-Pugh score uses five clinical measures of liver function (total bilirubin, serum albumin, ascites, hepatic encephalopathy, and prothrombin international normalized ratio [PT INR]) to categorize patients into Child-Pugh class A-C, which correlate with the severity of liver disease. ${ }^{36}$ The BCLC Staging System is currently a preferred staging system for HCC, and is endorsed by both the American and European Medical Associations. ${ }^{17,37-39}$

According to BCLC staging, very early-stage HCC includes patients with solitary, vaguely nodular tumors $<2 \mathrm{~cm}$, preserved liver function (Child-Pugh A), and no vascular or distant metastasis. Although these patients have the best prognosis, very early-stage HCC is difficult to diagnose. Early-stage disease includes patients with either solitary tumors $<5 \mathrm{~cm}$ or up to three nodules $<3 \mathrm{~cm}$ in size, no vascular invasion or extrahepatic dissemination (constituting the Milan criteria for liver transplantation), and Child-Pugh A or B liver function. Several curative treatment modalities are applicable in this patient subset, yielding a 5-year survival of $50-75 \%$. The intermediate stage includes patients with large multinodular tumors beyond the Milan criteria, Child-Pugh A or B liver disease, and no vascular tumor invasion or extrahepatic spread; these patients have an average predicted 3-year survival of $\sim 29 \%$ with current therapies. Advanced stage includes patients with Eastern Cooperative Group Performance Status (ECOG PS) 1 or 2 with tumors that may be accompanied by vascular invasion or extrahepatic spread;

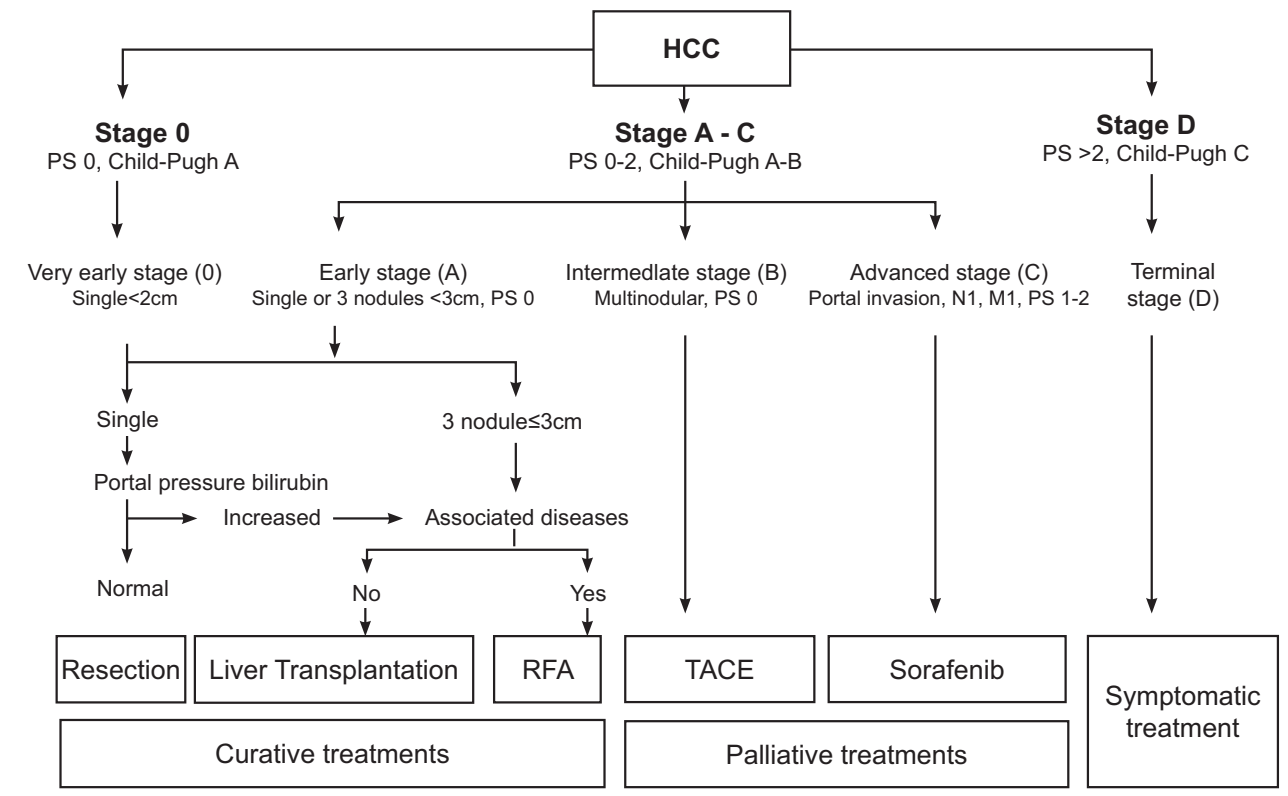

Fig. 2 Barcelona Clinic Liver Cancer Staging System for hepatocellular carcinoma (HCC). ${ }^{17}$ RFA, Radiofrequency ablation; TACE, transarterial chemoembolization. (Reprinted with permission from Bruix J, et al. Hepatology 2011; 53(3):1020-1022. Copyright John Wiley and Sons.) 
1-year survival rate is 50\%. End-stage disease includes patients exhibiting cancer symptoms and decompensated liver function (Child-Pugh $\mathrm{C}$ ); the median survival of this patient subset is $<3$ months. ${ }^{33}$

\section{Current Treatment Modalities for HCC}

The treatment strategy for a patient with HCC is selected based on cancer stage, patient performance status, and underlying liver disease, and includes radical surgery (resection or transplantation), locoregional therapy (radiofrequency ablation [RFA], transarterial chemoembolization [TACE], or embolization), systemic therapy (sorafenib), or a combination of these strategies.

\section{Early-Stage HCC}

Treatment options for patients with early-stage HCC are largely dictated by the severity of liver dysfunction, portal hypertension (defined as a hepatic venous pressure gradient $>10 \mathrm{~mm}$ $\mathrm{Hg}$ ), and presence of comorbidities. Surgical resection is the standard of care for patients with very early-stage or earlystage HCC with well-preserved liver function (no cirrhosis or Child-Pugh A), normal bilirubin $(<1 \mathrm{mg} / \mathrm{dL}$ ), and no portal hypertension. ${ }^{17}$ In patients with portal hypertension and elevated bilirubin ( $\geq 1 \mathrm{mg} / \mathrm{dL}$ ), a high risk of irreversible postoperative clinical decompensation and a reduced survival of $25 \%$ have been observed that preclude the use of surgical resection in this subset of patients. ${ }^{40}$ Unfortunately, earlyphase and late-phase intrahepatic recurrences have been reported after surgical resection, with 5-year recurrence rates exceeding $70 \%{ }^{41-43}$ Although predictors of recurrence have not been completely defined, there is some evidence to suggest that microvascular invasion and serum AFP $\geq 32 \mathrm{ng} / \mathrm{mL}$ might be strong predictive factors for postoperative early recurrence ( $<2$ years), although grade of hepatitis activity, tumor nodule multiplicity, and gross tumor classification may predict late recurrence ( $\geq 2$ years). ${ }^{42-46}$ Some evidence indicates that adjuvant therapy with interferon may reduce the risk of recurrence; however, further validation is required before its role can be established in this setting. ${ }^{47,48}$ Salvage transplantation may be indicated for selected previously resected patients such as those with recurrences due to de novo oncogenesis or those who show pathological evidence of vascular invasion prior to proven recurrence. ${ }^{49,50}$

Liver transplantation offers the best survival benefit for patients with early-stage disease by reducing the potential for recurrence through the elimination of undetectable liver lesions and underlying liver disease. The above-mentioned Milan criteria are globally used to select patients for liver transplantation; patients receiving a transplant according to this criteria have a 4-year overall survival (OS) of 75\% and only an $8 \%$ risk of recurrence. ${ }^{51}$ To expand listing criteria for patients with HCC, the University of San Francisco (UCSF) developed modified criteria in which patients with a solitary lesion of $\leq 6.5 \mathrm{~cm}$ in diameter or $\leq 3$ lesions $\leq 4.5 \mathrm{~cm}$ with a total combined diameter of $\leq 8 \mathrm{~cm}$ are eligible for transplant. ${ }^{52}$ However, the UCSF criteria have not been formally adopted by United Network for Organ Sharing (UNOS) due to the scarcity of donor livers. The UNOS primarily uses the Model for End-Stage Liver Disease (MELD) criteria, a composite score of liver function parameters that assesses the risk of life-threatening liver failure, to allocate available livers for transplantation. Because MELD does not consider mortality risk from HCC, additional points are given for presence of HCC to prioritize for transplantation. The long waiting time between listing and transplantation has also led to strategies for increasing the donor pool, such as using living donors and split liver transplantation. ${ }^{17,53}$ In addition, withdrawal from the waiting list due to disease progression might be reduced by use of a locoregional "bridge therapy," such as TACE or ablation. ${ }^{54-57}$ There is evidence that response to preoperative TACE to "downstage" HCC led to better long-term survival following transplantation, particularly in patients that fit the Milan criteria. ${ }^{58,59}$ Importantly, the number of donors available for liver transplant has plateaued over the past 10 years to $\sim 1500$ /year for patients with $\mathrm{HCC}^{60}$ while the number of patients with HCC has grown significantly to over $28,000{ }^{4}$ Therefore, liver transplantation as a treatment for HCC is limited in its scope.

For patients who are unsuitable for surgical resection or liver transplantation, locoregional therapy using imageguided percutaneous tumor ablation methods is the treatment of choice. RFA has demonstrated a superior survival benefit compared with percutaneous ethanol injection in patients with early-stage HCC, particularly those with compensated liver disease (Child-Pugh A). ${ }^{61}$ Radiofrequency ablation was associated with a 5 -year os of $76 \%$ when used as frontline therapy in patients with resectable HCC by BCLC criteria, which is comparable to the survival rates achieved historically with surgical resection. ${ }^{62,63}$ Two prospective randomized trials demonstrated that RFA was as effective as surgical resection in terms of OS or recurrencefree survival while being less invasive and having fewer complications. ${ }^{64,65}$ These results question the use of surgical resection as standard first-line therapy in all patients with very early-stage HCC, and support consideration of RFA in this setting. However, RFA has several limitations and showed suboptimal results in patients with tumor size $>3 \mathrm{~cm}$ and perivascularly located tumors. ${ }^{66}$ To overcome these limitations, numerous refinements of ablation methods are under clinical testing, including laser ablation, microwave ablation, cryoablation light-activated therapy, and irreversible electroporation.

\section{Intermediate-Stage HCC}

Patients with large multimodal tumors, preserved liver function, and no vascular invasion or extrahepatic spread who are ineligible for radical surgical therapies or percutaneous ablation are usually treated with TACE. ${ }^{17}$ Transarterial chemoembolization involves the intra-arterial injection of a cytotoxic agent (doxorubicin, cisplatin, or mitomycin), with or without lipiodol, plus an embolic agent into the hepatic artery that supplies the tumor. In a meta-analysis of seven studies, TACE demonstrated a significant improvement in 2-year survival (odds ratio $=0.53 ; p=0.017$ ) compared with best supportive care. ${ }^{67}$ However, patient selection appears to 
be critical for achieving a survival advantage with this method. In the positive Barcelona study, a 2-year OS of $63 \%$ and objective responses of $35 \%$ were reported for patients treated with TACE, but $70 \%$ of them had compensated liver disease (Child-Pugh A) with no vascular invasion or extrahepatic spread. ${ }^{68}$ Another study found that among patients treated with TACE, those with unilobular portal vein invasion and tumors $>5 \mathrm{~cm}$ did not show a survival benefit. ${ }^{69}$ In both of these studies, the long-term outcomes were unsatisfactory with a 3-year OS of only $\sim 30 \%$, highlighting the need for improved strategies to optimize outcomes.

To further improve outcomes and tolerability of TACE, a new drug delivery system has been developed using doxorubicin-eluting beads (DEB), which provides embolization and releases the cytotoxic agent in a controlled fashion (DEB-TACE).$^{70}$ Encouraging tolerability and response rates of $70-85 \%$ have been reported with this technique. ${ }^{71-74}$ However, in the recently reported, prospective, randomized phase II PRECISION V trial of 212 patients with intermediatestage HCC, though DEB-TACE substantially reduced hepatic and doxorubicin-related systemic side effects compared with those found with conventional TACE, clear superiority in response rates was not demonstrated (52\% vs 44\%; $p=0.11) .{ }^{75}$ Clearly, further studies are warranted to define the role of DEB-TACE in HCC. In addition to TACE, radioembolization with yttrium-90 $\left({ }^{90} \mathrm{Y}\right)$ microspheres represents a potential new treatment option for patients with ChildPugh A cirrhosis and intermediate-stage HCC, but needs to be explored in randomized trials. ${ }^{76}$

\section{Unresectable|Advanced-Stage HCC}

Treatment options are limited for patients with unresectable advanced stage HCC or those for whom therapy with TACE has failed. Systemic chemotherapy, either single agent or in combination, demonstrated only minor antitumor activity (response rate $<30 \%$ ) and failed to show an unequivocal improvement in OS. ${ }^{77-79}$ However, recent evidence that chemotherapy might have a role in HCC has emerged from an Asian phase III study where the FOLFOX4 (oxaliplatin/5fluorouracil/leucovorin) chemotherapy regimen improved response rate, time to progression (TTP), and OS in patients with advanced stage HCC when compared with doxorubicin, but these results require further validation. ${ }^{80}$

Better understanding of the molecular pathogenesis of HCC has led to recognition of the importance of angiogenesis for tumor development, growth, and progression, thus making angiogenesis an attractive target. Proangiogenic factors, such as vascular endothelial growth factor (VEGF) and platelet derived growth factor (PDGF) and their receptors, have been shown to have important roles in facilitating HCC angiogenesis. Sorafenib, a multitargeted tyrosine kinase inhibitor that blocks several key modulators of angiogenesis, including VEGFR2, PDGFR, Raf-1 and B-Raf receptors, is the first drug to show a survival benefit in patients with advanced HCC and represents a paradigm shift in the systemic treatment of this disease. Its efficacy was proven in two large, randomized, placebo-controlled clinical trials, which mainly included patients with advanced HCC and Child-Pugh A liver dis- ease. ${ }^{81,82}$ In the Sorafenib HCC Assessment Randomized Protocol (SHARP) study of 602 patients, most of whom were Caucasian, treatment with $400 \mathrm{mg}$ sorafenib twice daily significantly prolonged TTP (5.5 months vs 2.8 months; $\mathrm{HR}=0.58 ; 95 \%$ confidence interval $[\mathrm{CI}]$ 0.45-0.74; $p<0.001)$ and median OS (10.7 months vs 7.9 months, $\mathrm{HR}=0.69 ; 95 \%$ CI $0.55-0.87 ; p<0.001)$. In a similarly designed Asia-Pacific study of 271 Asian patients, sorafenib therapy prolonged TTP (2.8 months vs 1.4 months; HR $=0.57 ; 95 \% \mathrm{CI} 0.42-0.72 ; p=0.0005)$ and median OS (6.5 months vs 4.2 months; $\mathrm{HR}=0.68$; $95 \%$ CI $0.50-0.93$; $p=0.014$ ) compared with placebo. The inferior magnitude of benefit of the Asia-Pacific study compared with the SHARP study may be partly attributable to differences in patient characteristics, disease heterogeneity, and etiopathology between the trials. Seventy-five percent of patients in the Asia-Pacific study exhibited hepatitis B etiology, compared with only $19 \%$ in the SHARP study. In addition, patients enrolled in the Asia-Pacific study had a worse performance status and more advanced stage disease in general than those in the SHARP study. In both trials, hand-and-foot skin reaction, diarrhea, rash, and fatigue were among the most commonly reported adverse effects.

In both of these studies of sorafenib in the treatment of HCC, the improvements in OS and TTP were not accompanied by benefit in terms of objective response, highlighting the lack of utility of conventional RECIST criteria for evaluation of tumor response to molecular targeted therapy. Recently developed modified RECIST ( $m R E C I S T$ ) criteria propose the assessment of response to molecular targeted therapy (or locoregional therapy) in patients with HCC based on measurement of viable tumor with arterial enhancement on a computed tomography scan, not anatomical tumor response. ${ }^{83}$ Although the mRECIST is utilized in the assessment of response in systemic therapies, it needs further validation. When response to sorafenib was assessed according to both mRECIST and conventional RECIST criteria in patients with advanced HCC, a higher rate of objective responses was identified with mRECIST (23\% vs $2 \%$ ), and patients who achieved a response according to mRECIST had a longer OS than nonresponding patients (18 months vs 8 months, $p=0.013){ }^{84}$

Although it is indisputable that sorafenib represents a major advancement in the management of unresectable advanced-stage HCC, several unanswered questions and unmet needs still remain. The clinical benefit with sorafenib appears to be modest and short-lived, even in patients with preserved liver function. In addition, there is currently no reliable predictive biomarker for monitoring response or indicating treatment resistance. The registrational trials also did not provide data on the safety and efficacy of sorafenib in patients with compromised liver function. However, the postapproval observational GIDEON study (Global Investigation of Therapeutic Decisions in Hepatocellular Carcinoma and of Its Treatment with Sorafenib) showed that sorafenib $400 \mathrm{mg}$ twice daily could be safely prescribed to selected Child-Pugh B patients. ${ }^{85}$ Sorafenib is also being examined in the neoadjuvant and adjuvant settings in combination with locoregional therapies. 


\section{Conclusion}

Recent years have witnessed significant changes in the management of HCC. Multidisciplinary approaches to management of this disease and diagnostic and treatment algorithms that accommodate the unique aspects of HCC, including its pathobiology, heterogeneity, and underlying liver impairment, have been developed. The introduction of sorafenib therapy has validated the targeted approach to this disease and represents a major paradigm shift in the treatment of advanced HCC, leading to the identification of other potential targets and the development of new targeted agents in HCC, which are discussed in the next article.

\section{Acknowledgments}

The author would like to thank Sabitha Muneer, PhD, Bojana Pajk, MD, MSc, Amy Furedy, RN, OCN, and Chelsey Goins, $\mathrm{PhD}$, for their assistance in writing the manuscript, and Trudy Grenon Stoddert, ELS, for her editorial assistance and assistance preparing the manuscript for publication. Financial support was provided through an educational grant from Bristol-Myers Squibb Co.

\section{References}

1 Ferlay J, Shin HR, Bray F, Forman D, Mathers C, Parkin DM. GLOBOCAN 2008 v1.2, Cancer Incidence, Mortality and Prevalence Worldwide: IARC CancerBase No. 10 [Internet]. Lyon, France: International Agency for Research on Cancer;2010. Available at: http://globocan.iarc.fr/. Accessed June 6, 2012

2 Jemal A, Bray F, Center MM, Ferlay J, Ward E, Forman D. Global cancer statistics. CA Cancer J Clin 2011;61(2):69-90

3 Altekruse SF, McGlynn KA, Reichman ME. Hepatocellular carcinoma incidence, mortality, and survival trends in the United States from 1975 to 2005. J Clin Oncol 2009;27(9):1485-1491

4 American Cancer Society. Cancer Facts \& Figures 2012. Atlanta, GA: American Cancer Society; 2012. Available at: http://www.cancer. org/acs/groups/content/@epidemiologysurveilance/documents/ document/acspc-031941.pdf. Accessed on January 21, 2012

5 London WT, McGlymm KA. Liver cancer. In: Schottenfeld D, Fraumeni FJ Jr, eds. Cancer Epidemiology and Prevention. 3rd ed. New York: Oxford University Press; 2006:763-786

6 Kiyosawa K, Umemura T, Ichijo T, et al. Hepatocellular carcinoma: recent trends in Japan. Gastroenterology 2004;127(5, Suppl 1): S17-S26

7 Donato F, Tagger A, Chiesa R, et al; for the BRESCIA HCC Study. Hepatitis $B$ and $C$ virus infection, alcohol drinking, and hepatocellular carcinoma: a case-control study in Italy. Brescia HCC Study. Hepatology 1997;26(3):579-584

8 Hassan MM, Hwang L-Y, Hatten CJ, et al. Risk factors for hepatocellular carcinoma: synergism of alcohol with viral hepatitis and diabetes mellitus. Hepatology 2002;36(5):1206-1213

9 El-Serag HB, Tran T, Everhart JE. Diabetes increases the risk of chronic liver disease and hepatocellular carcinoma. Gastroenterology 2004;126(2):460-468

10 Calle EE, Rodriguez C, Walker-Thurmond K, Thun MJ. Overweight, obesity, and mortality from cancer in a prospectively studied cohort of U.S. adults. N Engl J Med 2003;348(17):1625-1638

11 Marrero JA, Fontana RJ, Fu S, Conjeevaram HS, Su GL, Lok AS. Alcohol, tobacco and obesity are synergistic risk factors for hepatocellular carcinoma. J Hepatol 2005;42(2):218-224
12 Chen D-S. Toward elimination and eradication of hepatitis B. J Gastroenterol Hepatol 2010;25(1):19-25

13 Liaw Y-F, Sung JJ, Chow WC, et al; Cirrhosis Asian Lamivudine Multicentre Study Group. Lamivudine for patients with chronic hepatitis B and advanced liver disease. N Engl J Med 2004;351 (15):1521-1531

14 Ghany MG, Nelson DR, Strader DB, Thomas DL, Seeff LB; American Association for Study of Liver Diseases. An update on treatment of genotype 1 chronic hepatitis C virus infection: 2011 practice guideline by the American Association for the Study of Liver Diseases. Hepatology 2011;54(4):1433-1444

15 Röcken C, Carl-McGrath S. Pathology and pathogenesis of hepatocellular carcinoma. Dig Dis 2001;19(4):269-278

16 Thorgeirsson SS, Grisham JW. Molecular pathogenesis of human hepatocellular carcinoma. Nat Genet 2002;31(4):339-346

17 Bruix J, Sherman M; American Association for the Study of Liver Diseases. Management of hepatocellular carcinoma: an update. Hepatology 2011;53(3):1020-1022

18 Zhang BH, Yang BH, Tang ZY. Randomized controlled trial of screening for hepatocellular carcinoma. J Cancer Res Clin Oncol 2004;130(7):417-422

19 Singal A, Volk ML, Waljee A, et al. Meta-analysis: surveillance with ultrasound for early-stage hepatocellular carcinoma in patients with cirrhosis. Aliment Pharmacol Ther 2009;30(1):37-47

20 Thompson Coon J, Rogers G, Hewson P, et al. Surveillance of cirrhosis for hepatocellular carcinoma: systematic review and economic analysis. Health Technol Assess 2007;11(34):1-206

21 Lin OS, Keeffe EB, Sanders GD, Owens DK. Cost-effectiveness of screening for hepatocellular carcinoma in patients with cirrhosis due to chronic hepatitis C. Aliment Pharmacol Ther 2004;19 (11):1159-1172

22 Singal AG, Conjeevaram HS, Volk ML, et al. Effectiveness of hepatocellular carcinoma surveillance in patients with cirrhosis. Cancer Epidemiol Biomarkers Prev 2012;21(5):793-799

23 National Comprehensive Cancer Network. Clinical Practice Guidelines in Oncology: Hepatobiliary Cancers. V 2.2012. Available at: www.nccn.org. Accessed July 3, 2012

24 Silva MA, Hegab B, Hyde C, Guo B, Buckels JA, Mirza DF. Needle track seeding following biopsy of liver lesions in the diagnosis of hepatocellular cancer: a systematic review and meta-analysis. Gut 2008;57(11):1592-1596

25 Tremosini S, Forner A, Boix L, et al. Prospective validation of an immunohistochemical panel (glypican 3, heat shock protein 70 and glutamine synthetase) in liver biopsies for diagnosis of very early hepatocellular carcinoma. Gut 2012;61(10):1481-1487

26 Okuda K, Ohtsuki T, Obata H, et al. Natural history of hepatocellular carcinoma and prognosis in relation to treatment. Study of 850 patients. Cancer 1985;56(4):918-928

27 The Cancer of the Liver Italian Program (CLIP) Investigators. A new prognostic system for hepatocellular carcinoma: a retrospective study of 435 patients. Hepatology 1998;28(3):751-755

28 The Cancer of the Liver Italian Program (CLIP) Investigators. Prospective validation of the CLIP score: a new prognostic system for patients with cirrhosis and hepatocellular carcinoma. Hepatology 2000;31(4):840-845

29 Leung TW, Tang AM, Zee B, et al. Construction of the Chinese University Prognostic Index for hepatocellular carcinoma and comparison with the TNM staging system, the Okuda staging system, and the Cancer of the Liver Italian Program staging system: a study based on 926 patients. Cancer 2002;94(6):1760-1769

30 Kudo M, Chung H, Osaki Y. Prognostic staging system for hepatocellular carcinoma (CLIP score): its value and limitations, and a proposal for a new staging system, the Japan Integrated Staging Score (JIS score). J Gastroenterol 2003;38(3):207-215

31 Vauthey JN, Lauwers GY, Esnaola NF, et al. Simplified staging for hepatocellular carcinoma. J Clin Oncol 2002;20(6):1527-1536

32 Fleming ID. AJCC/TNM cancer staging, present and future. J Surg Oncol 2001;77(4):233-236 
33 Llovet JM, Brú C, Bruix J. Prognosis of hepatocellular carcinoma: the BCLC staging classification. Semin Liver Dis 1999;19(3):329-338

34 Forner A, Reig ME, de Lope CR, Bruix J. Current strategy for staging and treatment: the BCLC update and future prospects. Semin Liver Dis 2010;30(1):61-74

35 Child CG, Turcotte JG. Surgery and portal hypertension. In: Child CG, ed. The Liver and Portal Hypertension. Philadelphia, PA: Saunders; 1964:50-64

36 Pugh RN, Murray-Lyon IM, Dawson JL, Pietroni MC, Williams R. Transection of the oesophagus for bleeding oesophageal varices. $\mathrm{Br}$ J Surg 1973;60(8):646-649

37 Bruix J, Llovet JM. Major achievements in hepatocellular carcinoma. Lancet 2009;373(9664):614-616

38 Marrero JA, Fontana RJ, Barrat A, et al. Prognosis of hepatocellular carcinoma: comparison of 7 staging systems in an American cohort. Hepatology 2005;41(4):707-716

39 Llovet JM, Di Bisceglie AM, Bruix J, et al; Panel of Experts in HCCDesign Clinical Trials. Design and endpoints of clinical trials in hepatocellular carcinoma. J Natl Cancer Inst 2008;100(10):698711

40 Llovet JM, Fuster J, Bruix J; for the Barcelona Clinic Liver Cancer Group. Intention-to-treat analysis of surgical treatment for early hepatocellular carcinoma: resection versus transplantation. Hepatology 1999;30(6):1434-1440

41 Imamura H, Matsuyama Y, Tanaka E, et al. Risk factors contributing to early and late phase intrahepatic recurrence of hepatocellular carcinoma after hepatectomy. J Hepatol 2003;38(2):200-207

42 Shirabe K, Kanematsu T, Matsumata T, Adachi E, Akazawa K, Sugimachi K. Factors linked to early recurrence of small hepatocellular carcinoma after hepatectomy: univariate and multivariate analyses. Hepatology 1991;14(5):802-805

43 Poon RT, Fan ST, Lo CM, Liu CL, Wong J. Intrahepatic recurrence after curative resection of hepatocellular carcinoma: long-term results of treatment and prognostic factors. Ann Surg 1999;229 (2):216-222

44 Adachi E, Maeda T, Matsumata T, et al. Risk factors for intrahepatic recurrence in human small hepatocellular carcinoma. Gastroenterology 1995;108(3):768-775

45 Okada S, Shimada K, Yamamoto J, et al. Predictive factors for postoperative recurrence of hepatocellular carcinoma. Gastroenterology 1994;106(6):1618-1624

46 Morimoto O, Nagano H, Sakon M, et al. Diagnosis of intrahepatic metastasis and multicentric carcinogenesis by microsatellite loss of heterozygosity in patients with multiple and recurrent hepatocellular carcinomas. J Hepatol 2003;39(2):215-221

47 Mazzaferro V, Romito R, Schiavo M, et al; HCC Italian Task Force. Prevention of hepatocellular carcinoma recurrence with alphainterferon after liver resection in HCV cirrhosis. Hepatology 2006;44(6):1543-1554

48 Breitenstein S, Dimitroulis D, Petrowsky H, Puhan MA, Müllhaupt B, Clavien P-A. Systematic review and meta-analysis of interferon after curative treatment of hepatocellular carcinoma in patients with viral hepatitis. Br J Surg 2009;96(9):975-981

49 Majno PE, Sarasin FP, Mentha G, Hadengue A. Primary liver resection and salvage transplantation or primary liver transplantation in patients with single, small hepatocellular carcinoma and preserved liver function: an outcome-oriented decision analysis. Hepatology 2000;31(4):899-906

50 Sala M, Fuster J, Llovet JM, et al; Barcelona Clinic Liver Cancer (BCLC) Group. High pathological risk of recurrence after surgical resection for hepatocellular carcinoma: an indication for salvage liver transplantation. Liver Transpl 2004;10(10):1294-1300

51 Mazzaferro V, Regalia E, Doci R, et al. Liver transplantation for the treatment of small hepatocellular carcinomas in patients with cirrhosis. N Engl J Med 1996;334(11):693-699

52 Yao FY, Ferrell L, Bass NM, et al. Liver transplantation for hepatocellular carcinoma: expansion of the tumor size limits does not adversely impact survival. Hepatology 2001;33(6):1394-1403
53 Ioannou GN, Perkins JD, Carithers RL Jr. Liver transplantation for hepatocellular carcinoma: impact of the MELD allocation system and predictors of survival. Gastroenterology 2008;134(5): 1342-1351

54 Llovet JM, Mas X, Aponte JJ, et al. Cost effectiveness of adjuvant therapy for hepatocellular carcinoma during the waiting list for liver transplantation. Gut 2002;50(1):123-128

55 Stone MJ, Klintmalm GB, Polter D, et al. Neoadjuvant chemotherapy and liver transplantation for hepatocellular carcinoma: a pilot study in 20 patients. Gastroenterology 1993;104(1):196-202

56 Pokorny H, Gnant M, Rasoul-Rockenschaub S, et al. Does additional doxorubicin chemotherapy improve outcome in patients with hepatocellular carcinoma treated by liver transplantation? Am J Transplant 2005;5(4 Pt 1):788-794

57 Majno PE, Adam R, Bismuth $\mathrm{H}$, et al. Influence of preoperative transarterial lipiodol chemoembolization on resection and transplantation for hepatocellular carcinoma in patients with cirrhosis. Ann Surg 1997;226(6):688-701, discussion 701-703

58 Millonig G, Graziadei IW, Freund MC, et al. Response to preoperative chemoembolization correlates with outcome after liver transplantation in patients with hepatocellular carcinoma. Liver Transpl 2007;13(2):272-279

59 Clavien PA, Lesurtel M, Bossuyt PM, Gores G-J, Langer B, Perrier A; on behalf of the OLT for HCC Consensus Group. Recommendations for liver transplantation for hepatocellular carcinoma: an international consensus conference report. Lancet Oncol 2012;13(1): e11-e22

60 United States Department of Health and Human Services. Organ Procurement and Transplant Network. Available at: www.optn. transplant.hrsa.gov. Accessed June 28, 2012

61 Cho YK, Kim JK, Kim MY, Rhim H, Han JK. Systematic review of randomized trials for hepatocellular carcinoma treated with percutaneous ablation therapies. Hepatology 2009;49(2):453-459

62 Lencioni R, Crocetti L. Local-regional treatment of hepatocellular carcinoma. Radiology 2012;262(1):43-58

63 N'Kontchou G, Mahamoudi A, Aout M, et al. Radiofrequency ablation of hepatocellular carcinoma: long-term results and prognostic factors in 235 Western patients with cirrhosis. Hepatology 2009;50(5):1475-1483

64 Chen M-S, Li J-Q Zheng Y, et al. A prospective randomized trial comparing percutaneous local ablative therapy and partial hepatectomy for small hepatocellular carcinoma. Ann Surg 2006;243 (3):321-328

65 Livraghi T, Meloni F, Di Stasi M, et al. Sustained complete response and complications rates after radiofrequency ablation of very early hepatocellular carcinoma in cirrhosis: Is resection still the treatment of choice? Hepatology 2008;47(1):82-89

66 Lu DS, Yu NC, Raman SS, et al. Radiofrequency ablation of hepatocellular carcinoma: treatment success as defined by histologic examination of the explanted liver. Radiology 2005;234(3):954-960

67 Llovet JM, Bruix J. Systematic review of randomized trials for unresectable hepatocellular carcinoma: chemoembolization improves survival. Hepatology 2003;37(2):429-442

68 Llovet JM, Real MI, Montaña X, et al; Barcelona Liver Cancer Group. Arterial embolisation or chemoembolisation versus symptomatic treatment in patients with unresectable hepatocellular carcinoma: a randomised controlled trial. Lancet 2002;359(9319): $1734-1739$

69 Lo CM, Ngan H, Tso WK, et al. Randomized controlled trial of transarterial lipiodol chemoembolization for unresectable hepatocellular carcinoma. Hepatology 2002;35(5):1164-1171

70 Malagari K. Drug-eluting particles in the treatment of HCC: chemoembolization with doxorubicin-loaded DC Bead. Expert Rev Anticancer Ther 2008;8(10):1643-1650

71 Grosso M, Vignali C, Quaretti P, et al. Transarterial chemoembolization for hepatocellular carcinoma with drug-eluting microspheres: preliminary results from an Italian multicentre study. Cardiovasc Intervent Radiol 2008;31(6):1141-1149 
72 Song MJ, Park CH, Kim JD, et al. Drug-eluting bead loaded with doxorubicin versus conventional lipiodol-based transarterial chemoembolization in the treatment of hepatocellular carcinoma: a case-control study of Asian patients. Eur J Gastroenterol Hepatol 2011;23(6):521-527

73 Malagari K, Chatzimichael K, Alexopoulou E, et al. Transarterial chemoembolization of unresectable hepatocellular carcinoma with drug eluting beads: results of an open-label study of 62 patients. Cardiovasc Intervent Radiol 2008;31(2):269-280

74 Malagari K, Pomoni M, Kelekis A, et al. Prospective randomized comparison of chemoembolization with doxorubicin-eluting beads and bland embolization with BeadBlock for hepatocellular carcinoma. Cardiovasc Intervent Radiol 2010;33(3):541-551

75 Lammer J, Malagari K, Vogl T, et al; PRECISION V Investigators. Prospective randomized study of doxorubicin-eluting-bead embolization in the treatment of hepatocellular carcinoma: results of the PRECISION V study. Cardiovasc Intervent Radiol 2010;33 (1):41-52

76 Salem R, Lewandowski RJ, Mulcahy MF, et al. Radioembolization for hepatocellular carcinoma using Yttrium-90 microspheres: a comprehensive report of long-term outcomes. Gastroenterology 2010;138(1):52-64

77 Ihde DC, Kane RC, Cohen MH, McIntire KR, Minna JD. Adriamycin therapy in American patients with hepatocellular carcinoma. Cancer Treat Rep 1977;61(7):1385-1387

78 Sciarrino E, Simonetti RG, Le Moli S, Pagliaro L. Adriamycin treatment for hepatocellular carcinoma. Experience with 109 patients. Cancer 1985;56(12):2751-2755
79 Chlebowski RT, Brzechwa-Adjukiewicz A, Cowden A, Block JB, Tong $\mathrm{M}$, Chan KK. Doxorubicin $\left(75 \mathrm{mg} / \mathrm{m}^{2}\right)$ for hepatocellular carcinoma: clinical and pharmacokinetic results. Cancer Treat Rep 1984;68(3):487-491

80 Qin S, Bai Y, Ye S, et al. Phase III study of oxaliplatin plus 5fluorouracil/leucovorin (FOLFOX4) versus doxorubicin as palliative systemic chemotherapy in advanced HCC in Asian patients. J Clin Oncol 2010;28(15S): Abstract 4008

81 Llovet JM, Ricci S, Mazzaferro V, et al; SHARP Investigators Study Group. Sorafenib in advanced hepatocellular carcinoma. N Engl J Med 2008;359(4):378-390

82 Cheng AL, Kang YK, Chen Z, et al. Efficacy and safety of sorafenib in patients in the Asia-Pacific region with advanced hepatocellular carcinoma: a phase III randomised, double-blind, placebo-controlled trial. Lancet Oncol 2009;10(1):25-34

83 Lencioni R, Llovet JM. Modified RECIST (mRECIST) assessment for hepatocellular carcinoma. Semin Liver Dis 2010;30(1):52-60

84 Edeline J, Boucher E, Rolland Y, et al. Comparison of tumor response by Response Evaluation Criteria in Solid Tumors (RECIST) and modified RECIST in patients treated with sorafenib for hepatocellular carcinoma. Cancer 2012;118(1):147-156

85 Marrero J, Lencioni R, Kudo M, et al. Global Investigation of Therapeutic Decisions in Hepatocellular Carcinoma and of Its Treatment with Sorafenib (GIDEON) second interim analysis in more than 1,500 patients: clinical findings in patients with liver dysfunction. J Clin Oncol 2011;29(Suppl): Abstract 4001 